\title{
Health Disparities and the Future of Environmental Justice Advocacy: Incrementalism, Punctuated Equilibrium, and the Way Forward
}

\author{
Sima Namin and Kirsten Beyer
}

\begin{abstract}
The unequal burden of environmental hazards in minority communities has been widely studied in environmental justice (EJ) research, mainly motivated by health disparities among minority populations. This article provides an overview of EJ legislation, policies and trends, and potential future directions. First, we examine EJ policies and legislation introduced in the United States as a measure of political attitudes to provide a big picture of the general political attitudes toward EJ. Second, we use institutional incrementalism and punctuated equilibrium frameworks to examine historical changes in this multifaceted policy area. We argue that the overall picture is more aligned with punctuated equilibrium and that the punctuated nature of EJ policy highlights the important role of local environmental activism as a form of policy inertia to challenge the status quo. Moreover, by analyzing the central themes of EJ policies (health, health disparities, and cancer disparities), we conclude that the essence of environmental activism should evolve into a more interdisciplinary platform with a focus on health disparities and preventive measures for more effective framing of EJ discourses.
\end{abstract}

Keywords: environmental justice, health disparities, incrementalism, punctuated equilibrium

\section{INTRODUCTION}

$\mathbf{O}$ Nebruary 11, 1994, President Bill Clinton issued Executive Order 12898 that required Federal actions to address environmental justice (EJ) in minority populations and low-income populations. Thus, after decades of advocacy, the EJ movement entered into the realm of policy and became a Federal priority. It is important to note that the executive order is a management tool for the government and it is not a law. ${ }^{1}$

Dr. Namin is an Instructor/Fellow at Institute for Health \& Equity, Medical College of Wisconsin, Milwaukee, Wisconsin, USA. Dr. Beyer is an Associate Professor at Institute for Health $\&$ Equity, Medical College of Wisconsin, Milwaukee, Wisconsin, USA.

${ }^{1}$ B. Wilson, B. Hill, Q. Pair, and S. Ruhl. "The State of Environmental Justice: An Obama Administration Retrospective." Environmental Law Reporter 47 (2017).
In 2008, one of the promises of President Barack Obama's campaign was to strengthen the Environmental Protection Agency (EPA) and to expand the EJ small grants program. During his administration, Federal commitment to Executive Order 12898 was re-established and EJ Interagency Working Group reconvened in $2010 .^{2}$ In addition, the focus on application of grants for community cumulative assessment and engagement with the National Environmental Justice Advisory Council led to Plan EJ 2014 as a roadmap for integrating EJ into different EPA programs. ${ }^{3}$ During this time, EJ became one of the top priorities of EPA's agenda and Plan EJ 2014 was

${ }^{2}$ J.Z. Paben and J. Zokovitch Paben. "Plan EJ 2014: Fact or Fiction? A Critique of the Obama Administration's Efforts on Environmental Justice." Wm. \& Mary Envtl. L. \& Pol'y Rev 41 (2016): 1-54.

${ }^{3}$ National Environmental Justice Advisory Council (NEJAC). "NEJAC Comments to EPA Plan EJ 2014". (2011). <https:// www.epa.gov/sites/production/files/2015-02/documents/plan-ej2014-comments-0511.pdf> (Last accessed on August 15, 2020). 
developed to strengthen community-based programs and capacity building in minority communities. ${ }^{4}$

The 2016 election of Donald J. Trump in 2016 introduced immediate change in direction and unprecedented challenges for hard-won environmental regulations, magnifying the power struggles at different levels of the government. Significant changes in the EPA's direction given changes in leadership are expected and this very fact has disturbed the efforts for a sustained commitment to the promises of EJ, and consequently, environmental health disparities. However, the Trump administration's commitment to the reversal of environmental regulations is unprecedented in recent history. Decisions to withdraw from the Paris Climate Agreement and to facilitate the Dakota access pipeline marked the new administration's stance on EJ issues early on, and by extension, signaled a new lack of interest in the well-being of low-income and minority communities in the United States and around the globe. ${ }^{5}$ In more than 80 rulemakings, the Trump administration has reversed more than 60 environmental rules and regulations, and 34 rolled backs and reversals in progress. ${ }^{6}$ More recently, he removed the support from the World Health Organization and has targeted the dismantlement of the National Environmental Policy Act, the hallmark environmental regulation that has provided environmental protection for half a century. ${ }^{7}$

However, it should be mentioned that although the Trump administration is using federal legislative power and tools at its disposal more aggressively than its predecessors may have done, the debate surrounding advantages and drawbacks of Federalism for environmental governance goes back decades. ${ }^{8,9,10}$ Environmental Federalism in the United States is designed on the basis of cooperation and partnership. ${ }^{11}$ But the functionality of

\footnotetext{
${ }^{4}$ David M. Konisky. "Federal Environmental Justice Policy: Lessons Learned.” In: David M. Konisky (ed). Failed Promises: Evaluating the Federal Government's Response to Environmental Justice. (The MIT Press: Cambridge, 2015), 233-59.

${ }^{5}$ Uma Outka and Elizabeth Ann Kronk Warner. "Reversing Course on Environmental Justice under the Trump Administration." Wake Forest Law Review 54 (2019): 393-422.

${ }^{6}$ Nadja Popovich, Livia Albeck-Ripka, and Kendra PierreLouis. "The Trump Administration Is Reversing 100 Environmental Rules. Here's the Full List.-The New York Times." The New York Times (May 2020). <https://www.nytimes.com/ interactive/2020/climate/trump-environment-rollbacks.html> (Last accessed on August 15,2020).

${ }^{7}$ Jeff Brady. "President Trump Announces Changes To National Environmental Policy Act Regulations: NPR." NPR (Jul 2020). <https://www.npr.org/2020/07/15/891563712/presidenttrump-announces-changes-to-national-environmental-policy-actregulatio $>$ (Last accessed on August 15, 2020).

${ }^{8}$ Richard B. Stewart. "Pyramids of Sacrifice? Problems of Federalism in Mandating State Implementation of National Environmental Policy." Yale Law Journal 86 (1977): 1196-1272.

${ }^{9}$ Barry Rabe. "Contested Federalism and American Climate Policy." Publius: The Journal of Federalism 41 (2011): 494-521.

${ }^{10}$ David M. Konisky and Neal D. Woods. "Environmental Federalism and the Trump Presidency: A Preliminary Assessment." Publius: The Journal of Federalism 48 (2018): 345-371.

${ }^{11}$ Dennis C. Cory and Tauhidur Rahman. Environmental Justice and Federalism. (Edward Elgar Publishing Limited: Northhampton, 2012).
}

this design becomes significantly limited by strong partisanship, populism, and devolved cooperation, as has been the case in the United States for decades. ${ }^{12,13}$

Modern Federalism is the foundation of the U.S. government and promises to provide EJ rights for all by securing a healthy environment. ${ }^{14}$ However, as witnessed in the past, EJ discourse usually fights its way into the mainstream dialogue when a massive tragedy is involved (e.g., Love Canal in 1978 and Warren County, North Carolina in 1982) and in the past few decades many have studied the potential and shortcomings of addressing EJ at different levels of U.S. government. ${ }^{15,16}$ From lead poisoning to fracking and air pollution, local EJ advocates struggle with a variety of obstacles to get the attention of policymakers. ${ }^{17,18}$ And they continue to face the challenges of dealing with Federal and State powers, to invoke different scales and to push EJ discourses. ${ }^{19}$

Consequently, debates over federalism and environmental policy and governance usually focus on the question of which level of government has the ultimate power to enact or ban a policy. This ongoing power struggle in the context of the shared responsibility model of EPA is captured in Pruitt's euphemism "cooperative federalism." 20 But these struggles are not just reflected in environmental policy; debates over health care reform in the United States are on the top of policy issues at State and Federal levels. Many scholars have studied the context and historical changes in both environmental and health policy areas in the context of

\footnotetext{
${ }^{12}$ E. DeNicola and P.R. Subramaniam. "Environmental Attitudes and Political Partisanship." Public Health 128 (2014): 404-409.

${ }^{13}$ David Konisky and Christopher McGrory Klyza. "Power, Partisanship, and Contingency: The President and U.S. Environmental Policy." In: David Konisky (ed). Handbook of U.S. Environmental Policy. (Edward Elgar Publishing, 2020), 11-24.

${ }^{14}$ David M. Konisky and Neal D. Woods. "Environmental Policy, Federalism, and the Obama Presidency." Publius: The Journal of Federalism 46 (2016): 366-391.

${ }^{15}$ H.M. Hoffmann. "Congressional Plenary Power and Indigenous Environmental Stewardship: The Limits of Environmental Federalism." Oregon Law Review 97 (2019): 353-383.

${ }^{16}$ D.M. Konisky. "Environmental Justice Delayed: Failed Promises, Hope for the Future." Environment 58 (2016): 4-15.

${ }^{17}$ J.L. Rice and B.J. Burke "Building More Inclusive Solidarities for Socio-Environmental Change: Lessons in Resistance from Southern Appalachia." Antipode 50 (2018): 212-232.

${ }^{18}$ D.H.Z. Williamson, E.X. Yu, C.M. Hunter, J.A. Kaufman, K. Komro, N.O. Jelks, D.A. Johnson, M.O. Gribble, M.C. Kegler. "A Scoping Review of Capacity-Building Efforts to Address Environmental Justice Concerns." International Journal of Environmental Research and Public Health 17 (2020): 3765 .

${ }^{19}$ Hilda E. Kurtz. "Scale Frames and Counter-Scale Frames: Constructing the Problem of Environmental Injustice." Political Geography 22 (2003): 887-916.

${ }^{20}$ David M. Konisky and Neal D. Woods. "Environmental Federalism and the Trump Presidency: A Preliminary Assess-
} ment." Publius: The Journal of Federalism 48 (2018): 345-371. 
U.S. Federalism. ${ }^{21,22,23,24}$ Two major models for tracking and analyzing policy change are incrementalism and punctuated equilibrium. ${ }^{25}$ Incrementalism, as captured in the notion of "muddling through," is the evolution of policy within the limits and conditions in which decision making occurs. ${ }^{26}$ This approach to changing the status quo is marked by "small and reversible steps" that minimize political loss in the face of opposition. ${ }^{27}$ In practice, this means that policymakers consider viable options within political and budgetary limits to secure agreements and reduce the burden of the uncertainty of outcomes. $^{28}$

However, there are areas and temporal episodes in which policy change occurs more rapidly with punctuated changes followed by a period of stability. Punctuated equilibrium theory ${ }^{29}$ has been increasingly applied in studies of sectoral policy. ${ }^{30}$ This model builds on incrementalism and maintains that the process of policy change is marked by punctuated and disruptive episodes. Revealing the patterns of stability and punctuations is usually done through examination of press coverage, government documents, and relevant regulations pertaining to a specific policy issue. ${ }^{31}$

Since the history of the EJ movement is short, there are not many studies on EJ policy trends and such analysis suffers from this limitation. In this article, we examine EJ policies within the broader environmental policy arena in relation to two models of policy change-incrementalism and punctuated equilibrium. We particularly focus on the patterns, including periods of stability and punctuated changes. We look at policy trends using congressional bills as measures of attention. Then, we focus on the

\footnotetext{
${ }^{21}$ David M. Konisky and Neal D. Woods. "Environmental Policy, Federalism, and the Obama Presidency." Publius: The Journal of Federalism 46 (2016): 366-391.

${ }^{22}$ Dennis C. Cory and Tauhidur Rahman. Environmental Justice and Federalism. (Edward Elgar Publishing Limited: Northhampton, 2012.

${ }^{23}$ Scott L. Greer and Peter D. Jacobson. "Health Care Reform and Federalism." Journal of Health Politics, Policy and Law 35 (2010): 203-226.

${ }^{24}$ Jamila Michener. Fragmented Democracy: Medicaid, Federalism, and Unequal Politics. (Cambridge University Press: Cambridge, 2018).

${ }^{25}$ David Benson and Duncan Russel. "Patterns of EU Energy Policy Outputs: Incrementalism or Punctuated Equilibrium?" West European Politics 38 (2015): 185-205.

${ }^{26}$ Charles E. Lindblom. "The Science of "Muddling Through." Public Administration Review 19 (1959): 79-88.

${ }^{27}$ John S. Dryzek and Patrick Dunleavy. Theories of the Democratic State. (Palgrave Macmillan, 2009).

${ }^{28}$ Manuele Citi. "EU Budgetary Dynamics: Incremental or Punctuated Equilibrium?" Journal of European Public Policy 20 (2013): 1157-1173.

${ }^{29}$ R. Frank. Baumgartner and Bryan D. Jones. Agendas and Instability in American Politics. (University of Chicago Press, 1993).

${ }^{30}$ Peter John. "Theories of Policy Change and Variation Reconsidered: A Prospectus for the Political Economy of Public Policy." Policy Sciences 51 (2018): 1-16.

${ }^{31}$ Jill McNew-Birren. "AAll Policy Is Local': Punctuated Equilibrium Theory and the Politics of US Lead Regulation." Environmental Politics 24 (2015): 681-702.
}

overlaps of discourse between EJ and health disparities. We argue that EJ policy does not follow a consistent incremental change pattern and that the historical trend of EJ policy shows defining punctuated episodes. The implications of this punctuated pattern of EJ are twofold: It is important to examine the episodes of discontinuity and disruption (1) to identify the determinant factors of change and structural weaknesses in policy reform capacity, and (2) to identify social processes and institutional inertia effects on legislative output.

\section{DATA AND METHODS}

The main sources of data used in this article are U.S. Congressional records (https://www.congress.gov/ congressional-record) and U.S. Government Regulation Track (https://www.govtrack.us/). The time span is almost 40 years from 1975 to 2020 . We used the search terms: ((Environmental justice) OR (environmental injustice) OR (environmental equity) OR (environmental inequity) OR (environmental health) OR (environmental quality)) to compile a list of all the legislation introduced by Congress and the Senate. We scanned each text to extract the main themes related to $\mathrm{EJ}$ in each regulation introduced. This study did not require IRB review.

Given that EPA categorizes many cumulative environmental risk factors as cancer and non-cancer (e.g., NATA), we categorized the results under three main themes: EJ, EJ and non-cancer health disparities, and EJ and cancer disparities. To analyze EJ discourses in the policy arena, we used these three themes. The "EJ" theme does not directly mention health disparities or public health concerns, "EJ and non-cancer health" directly discusses EJ issues in relation to non-cancer health disparities and/or public health concerns, and "EJ and cancer" in addition to health disparities specifically brings up the issues of cancer burden in EJ populations. This classification serves two purposes: (1) We can see how the framing around EJ and health has changed over time, and (2) given that cancer is the second leading cause of death in the United States and carcinogens are a growing burden in native and minority communities locating the place of cancer prevention discourse in EJ advocacy is important.

It should be noted that some records included all three themes whereas others were only focused on EJ without explicit mention of health, health disparities, or cancer. Also, we recorded the results based on three categories: failed, died, and enacted. Resolutions are not included in this assessment, but amendments with specific reference to EJ issues have been included in the final list. The compiled list does not include the results for the bills introduced in 2019-2020 sessions, because their results are mostly pending. We performed descriptive statistics to visualize the results.

\section{RESULTS}

Figure 1 shows EJ related bills introduced in Congress based on their outcome. The figure shows three episodes 


\section{Environmental Justice Related Bills Introduced in Congress and Senate}

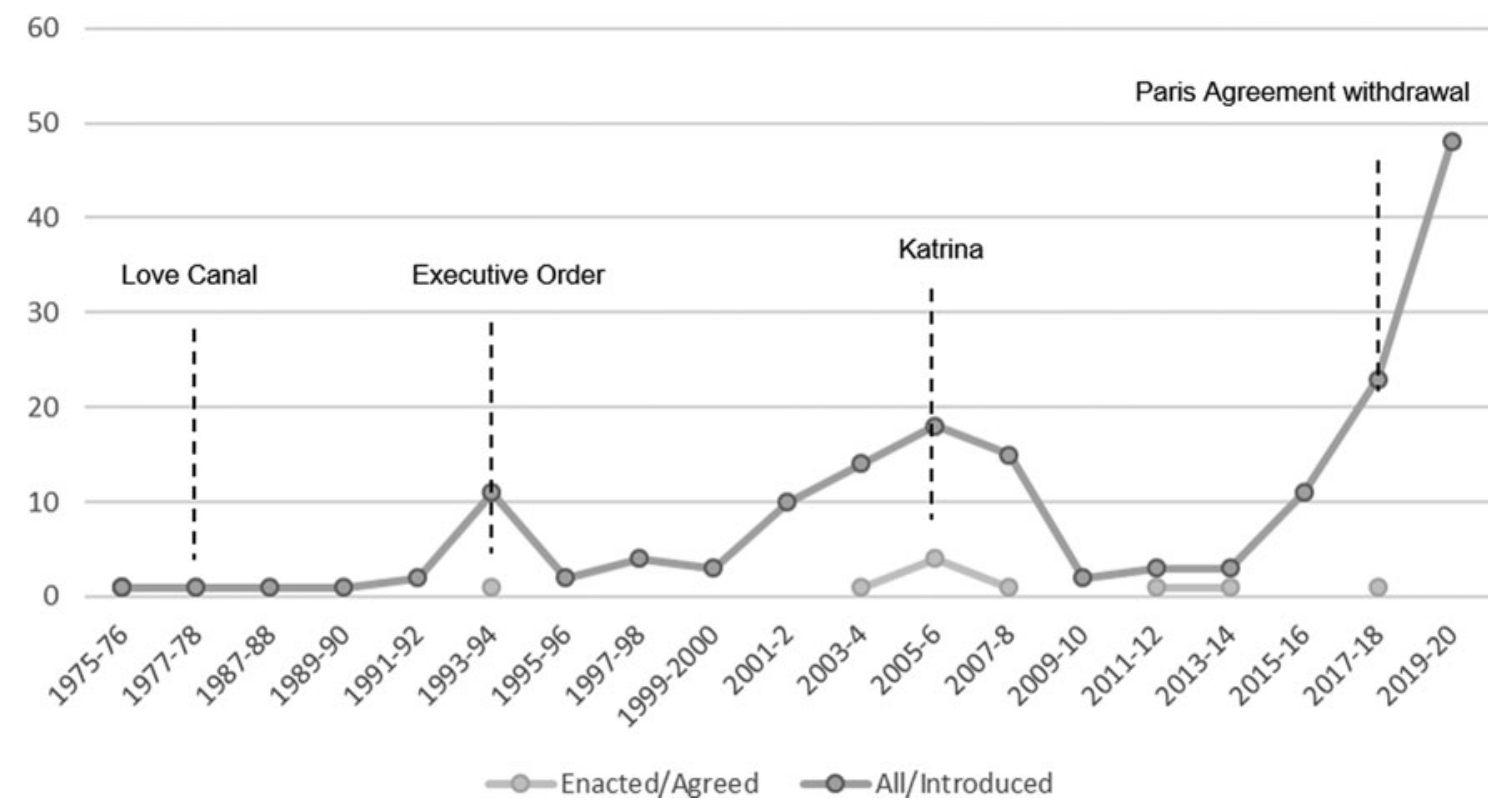

FIG. 1. EJ related policies introduced in Congress and Senate from 1975 to 2020. EJ, Environmental Justice. Source: Based on the Data Available at www.congress.gov

of rise in attention to EJ. The concepts of positive and negative feedback here are useful to explain the fluctuations. In the policy context, negative feedback refers to the forces that resist change and push for return to the original point. Positive feedback, however, is a driving factor of change. The main categories of negative feedback in the United States are structural, institutional, and behavioral systems. ${ }^{32}$ In the EJ policy arena, the counterplay between positive and negative feedback has long been recognized, and institutional discrimination and the structural problem of the burden of proof are the main sources of negative feedback.

As marked in Figure 1, the first spike in the 1990s coincides with the executive order No.12898 during the Clinton Administration. Before the executive order, the Office of Environmental Justice was created in 1992 to provide technical and financial assistance to EJ populations. Therefore, the federal government became the leading agency in EJ policy. Also, in 1992, the first EJ act was introduced in congress and was followed by similar bills in the following years. However, to this day, no EJ act has passed the House and EPA's environmental laws remain the only protection for EJ populations.

The second punctuation happened during the George W. Bush administration and can be partially explained by the devastating effects of hurricane Katrina that caused a surge of policy debates over the structural inequalities

\footnotetext{
${ }^{32}$ Robert C. Repetto. Punctuated Equilibrium and the Dynamics of U.S. Environmental Policy. (Yale University Press, 2006).
}

embodied in settlement patterns and persistent issues of EJ specifically in Louisiana and Coastal Mississippi. In this era, Congressional Black Caucus was one of the leading forces in introducing EJ legislations and amendments to clean air and water acts. However, almost all these bills died in congress and EJ remained in Federal legislative power. During the Obama administration, the EJ-related legislation activities in congress decreased, which can be explained by the progress made and supported by the white House that affected the need for positive feedback on EJ policy.

The third episode emerged in the first years of Trump administration, which is marked by deregulation and rollbacks. The abuse of the federal legislation power in the past 4 years has caused a dramatic increase in the congressional legislation activities. If having the White House as the driving force for EJ policy led to monumental improvements in the Obama's administration, it completely backfired in Trump era and highlighted the necessity for Federal and State EJ laws.

It should be mentioned that from 1975 to the present, more than $89 \%$ of the EJ related bills introduced in Congress and the Senate have been introduced by Democrats. Further, $30 \%$ of all the EJ related bills introduced by Republican representatives are explicit defunding of EPA or EJ programs, making EJ one of the policy issues affected by strong partisanship. It explains why two big punctuated episodes in legislation activities happened under Republican presidents.

As Figure 2 shows, concerns over environmental carcinogens have been a part of EJ legislative discourse since the 1970s. But the discourse around non-cancer 


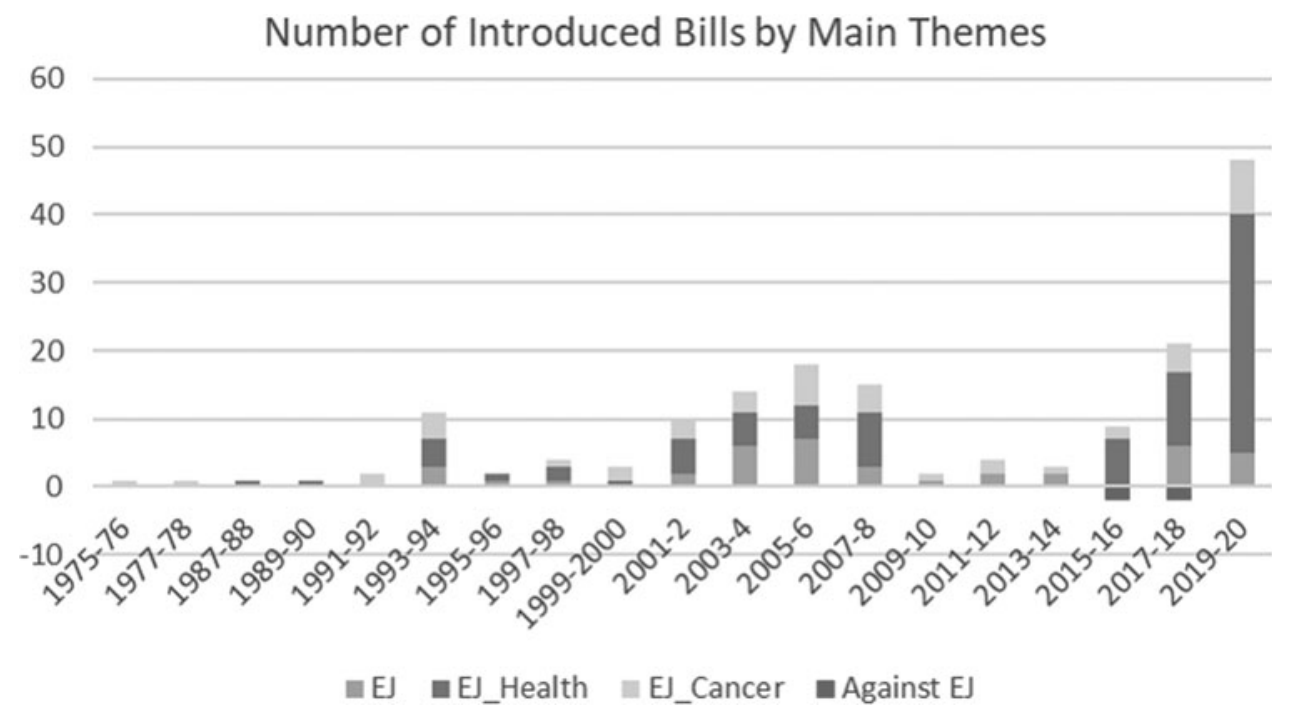

FIG. 2. EJ-related policies introduced in Congress and Senate from 1975 to 2020 based on main themes. Source: Based on the Data Available at www .congress.gov health issues associated with EJ has grown exponentially in the past decade. Moreover, counter EJ bills are now part of the policy battle, which highlights the punctuated episode starting in 2016. This episode of attention can be explained by the surge of drawbacks on environmental legislation. Constant attacks on environmental regulations have, in turn, generated a great deal of attention to EJ issues that can be interpreted as positive feedback that aims at combating the rollbacks and advocates for advancing EJ policies. Another noteworthy aspect of the third punctuated episode is the introduction of the Green New Deal as an intersectional climate change/EJ and health equity policy that embodies the essence of positive feedback for advancing EJ agenda.

\section{DISCUSSION}

The aim of this article was twofold: to investigate the general pattern of EJ policy based on the current literature on incrementalism and punctuated equilibrium, and to assess the central themes in EJ policy and legislation. The analysis of EJ-related introduced bills showed that punctuated equilibrium better explains the trend in congressional legislation efforts in EJ policy. However, these efforts for the most parts have been fruitless and EJ has remained at the mercy of Federal power. Moreover, the results of the progressive bills such as the Green New Deal and Climate Equity Act will reveal whether the current episode will lead to punctuated policy change for EJ or whether it has the symbolic resemblance of punctuated change.

It is important to remember that maybe more than any other topic, environmental policies are challenged consistently. ${ }^{33}$ Although the American environmental movement flourished during the 1970s, decades later, EJ

\footnotetext{
${ }^{33}$ R.C. Repetto. Punctuated equilibrium and the dynamics of U.S. environmental policy. (Yale University Press, 2006).
}

is still in the process of establishing regulations, ${ }^{34}$ and more recently fighting for previously in place regulations and enforcements; a fact that is highlighted with its punctuated nature and lack of stability in policy trends.

Figure 3 shows the main determinant factors of EJ. As summarized in this figure, current states of environmental (in) justice can be analyzed by studying the patterns of land use, air pollution, clean water, transportation networks, food deserts, and access to other prerequisites of a healthy lifestyle, and these are reflected in the patterns of health disparities in both communicable and noncommunicable and chronic diseases that persist across the United States. The current health crisis created by the novel coronavirus and the disease COVID-19 has highlighted these patterns. ${ }^{35}$

Further, to analyze the evolution of EJ policies in the United States, it is important to note that EJ is inherently intertwined with broad environmental and health policies. Therefore, it would be logical to expect it to mirror the general trends in the environmental policy arena. However, there is a gap between the policy response to health issues and environmental concerns. The U.S. health care spending has been growing rapidly: It grew by $4.6 \%$ in 2018 , reaching $\$ 3.6$ trillion total, or $\$ 11,172$ per person ${ }^{36}$ whereas Trump's proposed cuts would bring

\footnotetext{
${ }^{34}$ Onyemaechi C. Nweke, Devon Payne-Sturges, Lisa Garcia, Charles Lee, Hal Zenick, Peter Grevatt, William H. Sanders, Heather Case, and Irene Dankwa-Mullan. "Symposium on Integrating the Science of Environmental Justice into DecisionMaking at the Environmental Protection Agency: An Overview." American Journal of Public Health 101 (Suppl. 1) (2011): 19-26.

${ }^{35}$ S.M. Wilson, R. Bullard, J. Patterson, and S.B. Thomas. "Roundtable on the Pandemics of Racism, Environmental Injustice, and COVID-19 in America." Environmental Justice 13 (2020): 56-64.

${ }^{36}$ Centers for Disease Control and Prevention. "Health Expenditures." 2018. <https://www.cdc.gov/nchs/fastats/healthexpenditures.htm> (Last accessed on August 15, 2020).
} 


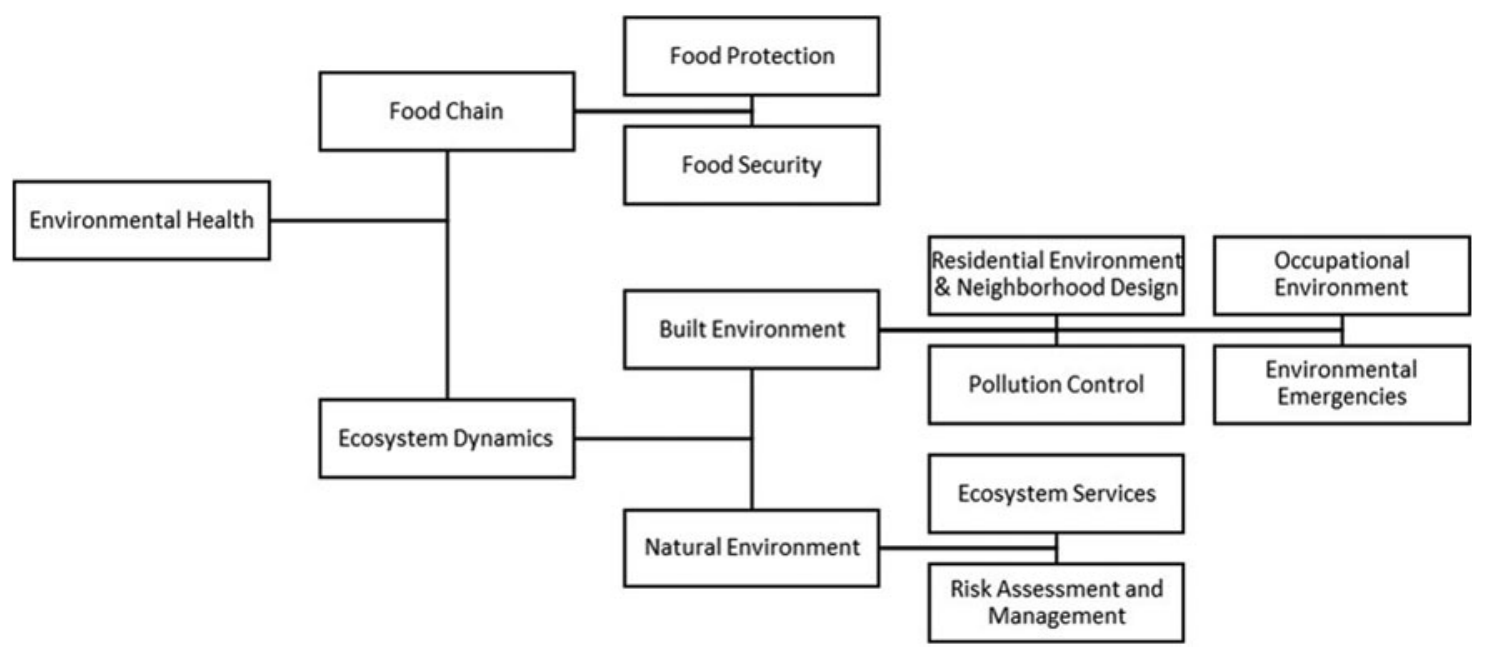

FIG. 3. Environmental health components of EJ in urban context.

the EPA's yearly costs down from $\$ 25$ per American to $\$ 18.81$ per American. ${ }^{37}$

Moreover, traditionally the role of federal government regulation has been considered a strong tool in protecting the environment. But recent major institutional and policy changes with a clear tendency toward more centralization and environmental deregulation highlight the role of public participation and local governments' endeavors to achieve EJ. ${ }^{38,39}$ Consequently, one of the main priorities of EJ agenda is adopting a public health model of prevention that is integrated with environmental and social concerns. ${ }^{40}$ As highlighted in Figure 2, in the past 4 years, the EJ discourse has focused on health and health disparities the most since its inception. This focus is now part of the positive feedback for policy change.

In addition, given the grass roots origins of EJ and its reliance on local mobilization, strengthening municipalities' power is essential. For example, local governments are now major players in creating climate action plans in the absence of a national agenda. ${ }^{41}$ And, therefore, they are the pioneering force in addressing environmental and public health concerns. As Figure 3 shows, many of the

\footnotetext{
${ }^{37}$ Save EPA. 2020. "How Much Do Environmental Protections Cost Taxpayers? | Save EPA." 2020.<http://saveepaalums .info/EPA+costs+to+taxpayers $>$ (Last accessed on August 15, 2020).

${ }^{38}$ C.M. Dhillon. "Using citizen science in environmental justice: participation and decision-making in a Southern California waste facility siting conflict." Local Environment 22 (2017): 1479-1496.

${ }^{39}$ A. Sarzynski. "Public participation, civic capacity, and climate change adaptation in cities." Urban Climate 14 (2015): 52-67.

${ }^{40}$ Julian Agyeman, Robert D. Bullard, and B. O. B. Evans. "Exploring the Nexus: Bringing Together Sustainability, Environmental Justice and Equity." Space and Polity 6 (2002): $37-41$.

${ }^{41}$ Thomas M. Gremillion. "Setting the Foundation: Climate Change Adaptation at the Local Level." Environmental Law 41 (2011): 1221-1253.
}

determinants of health inequalities such as food sovereignty and neighborhood improvements should be addressed locally. But local environmental laws are consistently preempted by States. ${ }^{42}$ If previously the Federal government was considered a force for pushing the EJ agenda in States, the current atmosphere highlights the importance of empowering local authority and enforcing local EJ achievements, especially when local governments decide to be more protective of human health and the environment than State and Federal governments. $^{43}$

\section{CONCLUSION}

The relationship between environmental health and human health almost successfully came out in the 1970s but has been consistently pushed back. ${ }^{44,45}$ Mobilizing public health discourse for $\mathrm{EJ}^{46}$ by using a socioecological model of health is essential, because addressing health inequalities is only possible through EJ.

Moreover, effecting policy change is possible through entering the policy process and therefore the future of any social movement is dependent on its ability to

\footnotetext{
${ }^{42}$ Shannon M. Roesler. "Federalism and local environmental regulation." UC Davis Law Rev 48 (2015): 1111-1172.

${ }^{43}$ Paul S. Weiland. "Preemption of local efforts to protect the environment: implications for local government officials." Virginia Environmental Law Journal 18 (1999): 467-506.

${ }^{44}$ E. Efron. Apocalyptics: Cancer and the Big Lie: How Environmental Politics Controls What We Know About Cancer. (Simon \& Schuster: New York, 1984).

${ }^{45}$ D.L. Davis and P.S. Webster. "The Social Context of Science: Cancer and the Environment." The ANNALS of the American Academy of Political and Social Science 584 (2002): $13-34$.

${ }^{46}$ American Public Health Association. "Achieving Environmental Justice in the 21st Century: The Way Forward." 2019. $<$ https://www.apha.org/events-and-meetings/apha-calendar/ webinar-events/2019/environmental-justice > (Last accessed on August 15, 2020).
} 
actively remain in the policy arena. ${ }^{47}$ Therefore, one concern for the EJ movement is long-term involvement in the policy processes and establishing EJ laws that will address health disparities in EJ communities. ${ }^{48}$ Integration of EJ research and preventive medicine is crucial in advancing the movement's ability to influence the policy-making processes and outcomes. Health disparity research with a focus on unequal exposure to environmental hazards and unequal access to healthy food and lifestyle options is closely associated with answers to the "how" question that can be used as catalysts to change the status quo of public policies around EJ discourse and empower the prevention medicine dialogue.

\section{DISCLAIMER}

These contents are solely the responsibility of the authors and do not necessarily represent the official views of the HRSA or the U.S. Department of Health and Human Services.

\section{AUTHOR DISCLOSURE STATEMENT}

No competing financial interests exist.

\section{FUNDING INFORMATION}

This work was partly supported by grant T32HP10030 from the Health Resources and Services Administration (HRSA), an operating division of the Department of Health and Human Services.

Address correspondence to: Sima Namin Department of Epidemiology Institute for Health \& Equity Medical College of Wisconsin 8701 Watertown Plank Rd. Milwaukee, WI 53226

USA

E-mail: snamin@mcw.edu

\footnotetext{
${ }^{47}$ Thomas R. Rochon and Daniel A. Mazmanian. "Social Movements and the Policy Process." The ANNALS of the American Academy of Political and Social Science 528 (1993): $75-87$.

${ }^{48}$ Robert D. Bullard and Glenn S. Johnson. "Environmentalism and Public Policy: Environmental Justice: Grassroots Activism and Its Impact on Public Policy Decision Making." Journal of Social Issues 56 (2000): 555-578.
} 